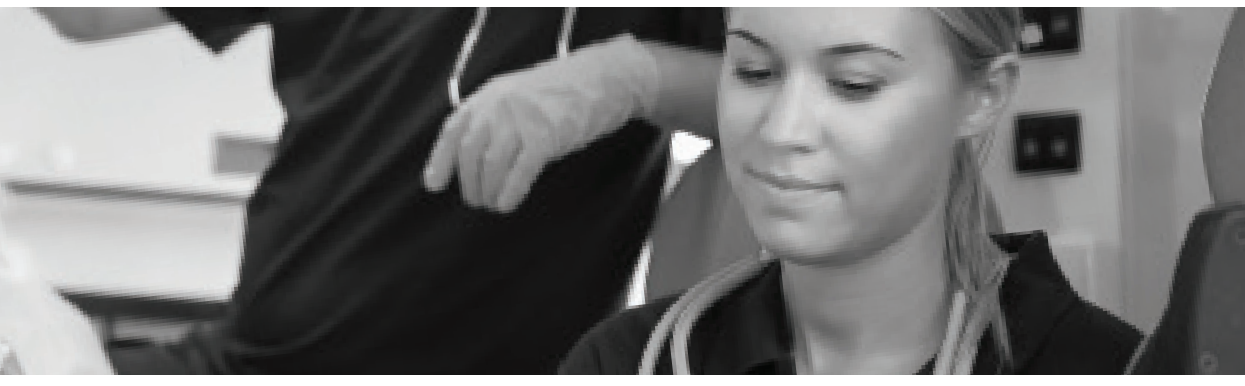

Volume 13 | Issue 1 | Article 3

\section{A USTRALASIAN JOURNALOF PARAMEDICINE}

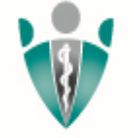

PARAMEDICS

\title{
Using a sociological approach to answering questions about paramedic professionalism and identity
}

Tania M Johnston

Charles Sturt University, Port Macquarie, New South Wales

Joe J Acker

Charles Sturt University, Port Macquarie, New South Wales 


\title{
Using a sociological approach to answering questions about paramedic professionalism and identity
}

Tania Johnston EMT-P(Hons), BSc(Nurs), MHS (leadership), MPA, is a PhD candidate ${ }^{1}$, Joe Acker EMT-P(Hons), MA (leadership), FPA, is a PhD candidate ${ }^{1}$

Affiliation:

${ }^{1}$ Charles Sturt University, School of Biomedical Sciences, Port Macquarie, New South Wales

\begin{abstract}
With evidence-based practice now the norm, paramedics today can confidently and readily search for answers to clinical questions. For anyone seeking to better understand the non-clinical aspects of paramedic practice, however, looking to social theory can be a starting point. Understanding social theory gives paramedic researchers a lens through which to closely examine every day events and behaviours that affect paramedic practice within the context of society. Arguably, the move towards professionalisation is one of the most significant events impacting paramedicine today. Alongside this professional evolution, the practitioner identity is gradually being challenged and reshaped, raising a number of important questions. The purpose of this article is to explore how paramedic researchers can use two prominent social theorists, Bourdieu and Goffman, to explore inevitable questions related to professions and professional identity.
\end{abstract}

Keywords:

paramedic; social theory; professionalism; professional Identity; research

Corresponding author: Tania Johnston, tjohnston@csu.edu.au 


\section{Background}

With evidence based practice (1) now the norm, paramedics today can confidently and readily search for answers to clinical questions. For anyone seeking to better understand the non-clinical aspects of paramedic practice, however, looking to social theory can be a starting point. Understanding social theory gives paramedic researchers a lens through which to closely examine everyday events and behaviours that affect paramedic practice within the context of society. Arguably, the move towards professionalisation $(2,3)$ is one of the most significant events impacting paramedicine today. The process of professionalisation described by Wilensky (1964) is summarised by Williams et al (2) as involving five steps:

\section{Development of a full-time occupation and formation of} occupational territory

2. Establishment of training schools or colleges; linkage to university education

3. Occupational promotion to national and international parties

4. Professional licensing and accreditation

5. Code of ethics is implemented.

Australian paramedics have been moving through these steps with support for professional registration heightened in recent months (4) and formally supported by the Council of Australian Governments (COAG) Health Council on November 6, 2015 (5). Alongside this professional evolution, the practitioner identity is gradually being challenged and reshaped, raising a number of important questions. Examples include: Do frontline paramedics feel that they are a discipline in transition? Do they see themselves as 'more professional' in the current climate? How do paramedics view their role in the midst of this change and how would they define themselves and their identity?

A starting point to explore these and other non-clinical questions raised by professionalisation begins with appreciating how social theory can both inform the questions and guide the research to answer them. The purpose of this article is to explore how paramedic researchers can use two prominent social theorists, Bourdieu and Goffman, to explore inevitable questions related to professions and professional identity. $A$ hypothetical case scenario is used to demonstrate application of theory to practice.

\section{Professionalisation}

Within the small body of global paramedic literature, professionalisation is an emerging topic, reflecting the current transition from semi-profession to professional status and subsequent maturation of the discipline $(2,3,6,7)$. The importance of further studying paramedic professionalism and ensuing questions of identity is apparent when one appreciates both the evolution of paramedicine and current challenges facing the discipline. Ambulance care in Australia, which humbly began with horse drawn carts in the 1880s, has evolved significantly with paramedics now assuming a key and indispensible position in health $(8,9)$. With demand for services increasing, there has been a notable role shift towards non-urgent care and a need for enhanced clinical decisionmaking and critical thinking on the part of paramedics (10). Positioned at the crossroads of emergency services and health care, it is becoming increasingly challenging to articulate what occupational territory is unique to paramedics (7). One constant is that paramedics remain adaptable and continue to fill gaps in health care delivery where and when needed (11).

\section{Occupational stress}

In the midst of these exciting yet daunting changes, paramedics are facing immense pressure. Research areas highlight high levels of occupational stress and persistent retention issues for paramedics (12-15). While the topic of critical incident stress has been prevalent in international paramedic literature for over 25 years (16), there are urgent calls for action over an alarming upward trend in paramedic post-traumatic stress and suicide rates (17-21). Paramedicine is evidently a discipline in crisis as well as in transition, suggesting it is timely to develop a contemporary identity while seeking answers that will ultimately increase resilience.

\section{Professional identity}

As nursing literature has demonstrated, role changes inevitably influence one's identity (22). Though the term is conceptually unclear, adopting a professional identity can be defined as 'connecting with roles, responsibilities, values and ethics unique to a specific profession' (23). Furthermore, developing a professional identity involves having a clear understanding of one's expected skills, knowledge and motivations (22). In a 2012 study on UK and US paramedic perspectives of research, the authors suggested that developing honest relationships with patients, focusing on patient benefit and having a strong orientation to the importance of timely treatments are key components of paramedic identities (24). Beyond this, as a young health discipline, little has been established with respect to a formal paramedic identity, though there is literature that attempts to illustrate the paramedic's personality characteristics. For example, given the traditional focus on emergency response and trauma care, the phrase 'trauma junkies' has been used to describe typical paramedics (25). Additionally, while popular television series have historically characterised paramedics as silent heroes and lifesavers (26), researchers have both identified and then refuted the stereotypical 'rescue personality' $(16,27-29)$. A recent study by social workers found care giving, thrill seeking, a unique capacity to provide services that others cannot, and a strong duty to respond as four domains of US paramedic role identity (30). As Donaghy notes, though stereotyping paramedics is common, their social identity should not be assumed (31). 
Today's paramedic may baulk at traditional stereotypes in light of the shift towards low acuity patient pathways and primary care interventions $(8,10)$, the move towards tertiary education $(31,32)$, and increased feminisation of the discipline $(10,32-34)$. With Australian paramedics now advancing through the steps of professionalisation $(2,5,35)$, it is time to question whether historical stereotypes and labels accurately represent the identity of paramedics today and into the future. In addition to connecting with a professions's skills, knowledge and motivation, it is the percepton of oneself that sets the stage for determining a professional identity (36). Taking lessons from medical professions who have followed a similar path (37), paramedic researchers can employ social theory as a starting point towards exploring questions of professional identity, an important area in need of further research (31).

\section{Social theory and paramedicine Why social theory}

Social theory gives us analytical frameworks, or lenses through which we can begin to make sense of the world around us (38). Looking at aspects of everyday life, sociology seeks to understand individual behaviour and interaction within a social context as well as how society changes over time $(39,40)$. Within the framework offered by dualism, or fundamental opposing distinctions, social theory examines some common themes including the nature of social life and social institutions, power structures, race, class and gender (40). The following case scenario will be used to illustrate how social theory can be applied to questions of professionalism and identity in paramedic practice.

\section{Case scenario}

It is the start of your shift when you are dispatched to an unconscious female, 68 years of age. Recognising the address, your rookie paramedic partner comments on the fact that you are attending to this frequent caller for the third time in 2 days. 'Angie is probably fighting with her partner again and has gone 'unconscious' to get his attention'. You both have a bit of a laugh as you leave the station, recalling how dramatic the scene was yesterday. When you arrive, the police are diffusing yet another domestic dispute, just as you predicted. Somehow the patient has sustained a minor laceration from a sharp object. The scene is deemed safe and the police officer points you in the direction of the patient who is by all accounts very conscious and appears well. The constable gives you a knowing look as you walk by her, discreetly rolling her eyes with a smile. 'Looks like it's an all female crew today' she remarks. As the treating officer, you perform a thorough patient history and assessment and complete all required documentation when Angie predictably refuses transport. Utilising your extended care skills, you suture closed a small laceration on her arm and administer a tetanus booster injection. Your partner contacts the local social work office and completes a referral for a follow up later in the day. Throughout the interaction, you act the consummate professional and never let on to the patient how you may be feeling about the situation. Once back in the ambulance however, you and your partner debrief the call and enjoy one final laugh before you are sent on your next job. This time you are requested to attend a palliative care patient at home requiring pain management; a community nurse is on scene. It's the rookie's turn to be treating officer and this is an unfamiliar situation for her. Though neither of you admit it, this next job will take its toll on both of you. As you start driving, you wonder what else the day will bring.

\section{Two social theorists - Goffman and Bourdieu}

In the 1950s, Erving Goffman, a Canadian, was observing communities in the Shetland Islands while concurrently, French scholar Jacques Bourdieu spent time observing the Kabyle people in northern Algeria. It would be reasonable for paramedics to ask how these two historical figures could contribute to our understanding of paramedic identity. Goffman and Bourdieu both became key contributors to social theory and the study of social phenomena. Their theories can be applied to real world problems through research specifically designed to answer questions related to paramedic practice (38). It is important to have a working understanding of these theorists and know how their writings can be used as a framework to further research about paramedic professionalism and identity. With reference to the above fictitious case scenario, the following section will present Goffman and Bourdieu while demonstrating how their theories can be applied to everyday paramedic practice.

\section{Goffman's Impression Management Theory}

Erving Goffman is well known for his interest in face-to-face interaction and use of theatre as a metaphor for social relations. He was keenly interested in how people interact with each other and behave. Goffman presented a 'theory of self' that served to examine the complex relationship between an individual 'actor' on stage and his or her 'audience' within the social context (41). In essence, he provided a conceptual tool to understand 'the black box connection between inner thought and observable action' (42). Goffman sought to understand symbolic value of verbal and non-verbal communication gestures (43) expressed by the actor who is intent on constructing and maintaining his or her reputation (41). He observed how individuals seek to emphasise gestures that support what they view as their 'desired self' while de-emphasising anything that may detract from the audience's favourable impression (43). As in a theatrical production, these interactions with the audience occur on what Goffman terms the front stage and backstage. Characterised as public, formal and restrained, the 'front stage' is where the actor delivers their convincing scripted performance (44), with an aim towards concealing their true self in terms of any attitudes or beliefs that may be seen as less desirable (41). Conversely, individuals use the informal and private 'backstage' area to relax out of character and often act in a contradictory manner while they rehearse for the front stage (44). Moving between the front and back regions, each with its own set of behavioural rules (43), constitutes what Goffman termed 'impression management' (41). His 'impression management' theory has been utilised by researchers who strive to better understand interactions involving health care professionals $(26,43,45-47)$. 


\section{Goffman and paramedicine}

When looking to better understand the role of paramedics and their professional identity, Goffman's theory can be used as a framework to analyse how paramedics interact within and outside of the discipline. The above case scenario presents an example of a contemporary paramedic work scenario. Two female paramedics with varying levels of experience and qualifications staff the ambulance. The requests for assistance are non-emergent and neither requires transport to a hospital. Both jobs will require the paramedics to interact with other professions. Finally, whether dealing with domestic violence or palliation, both patient encounters may have a lasting emotional impact on the team.

In the context of the above scenario, it is conceivable to imagine the paramedics as the individuals who become the actors once they put on the uniform and enter the workplace or 'stage'. The paramedic stage would include the station, the ambulance and the scene. Pre-hospital care involves regular interactions wherein the paramedic must perform in front of an audience on these stages while considering the impression they are making. Palmer (48) employed Goffman's theory to identify seven paramedic 'audiences' including the patient and their families, bystanders, ride-a-longs, colleagues, the media and emergency staff. In the case scenario presented, the audience would include the police, the patient, the family member and potentially the social worker. The paramedic's partner would also play the role of an audience member at certain times. The face-to-face interactions were very different during the treatment phase as compared to within the ambulance and out of sight of the patient. This is an illustration of Goffman's concepts of frontstage and backstage. All of the interactions throughout the job would have been managed to some extent with the intent of projecting a desirable image. On reputation management, Tangherlini (26) turned to Goffman to help explain how paramedics (the actors) present themselves to others (the audience) as 'being able to see it all without recoiling in disgust or terror'. A paramedic's reputation as competent, confident and trustworthy is important to foster and uphold. Goffman's impression management theory is certainly valuable in examining the role and interactions among paramedics both within and outside of the discipline and could conceivably be used to answer questions of paramedic identity.

\section{Bourdieu's Field Theory}

Whereas Goffman is known for impression and reputation management, Bourdieu has long been used to study professions. Known for his 'conflict perspective' wherein individuals struggle for power in society, Bourdieu examined how individuals relate to each other while competing for desirable resources within a given social setting $(38,49)$. Offering a view of professions as a social function (50), Bourdieu favoured sporting analogies and used terms such as game, player, field, rules and competition in his writings $(51,52)$. His theory advocates that studying 'relations' between people is key to understanding society (38) and therefore a starting point for studying professional identity.
Frustrated with research for the sake of academia, Bourdieu emphasised the importance of practically applying research to solve real world problems. To that end, he developed a theory of practice involving three interrelated conceptual tools he termed: habitus, field and capital. Habitus is described as one's personality structure, formed by a lifetime of experiences and education, that unconsciously influence how we relate to others (38). In the context of paramedicine, habitus could be interpreted to represent a paramedic's life experience prior to entering pre-hospital care, their paramedic training and experiences they have had since joining the discipline. Field is the conceptual area where individuals interact and compete for capital, or resources. The evolving paramedic profession, work environments and any social space wherein paramedics interact with colleagues or others could constitute the field. Capital represents power within a given field and is primarily categorised as economic (material goods or money), social (networks, group membership) or cultural (education, knowledge, or skills). Applying Bourdieu's theory of practice, paramedic economic capital would include seniority and pay while social capital would include membership in groups or classifications such as intensive care paramedic, extended care paramedic or flight paramedic, along with the real or perceived prestige that accompanies these positions. Examples of cultural capital in paramedicine would include clinical knowledge and skills, as well as participation in vocational or tertiary education. Though somewhat challenging to interpret, Bourdieu's theory has been applied across a number of health disciplines and is particularly useful for studying questions of professional practice and identity.

Returning to the case scenario, Bourdieu's field theory can be used to look beyond the surface to better understand the dynamics of the interactions. The field can be physically identified as the ambulance and scene in this case. The paramedic role as compared to that of the police officer, social worker and community nurse is also a component of the field. Each paramedic's educational background and previous life experience they bring to the role forms their habitus or paramedicself. Different forms of capital then influence the subsequent interactions and highlight any power imbalance at play. For example, the more experienced paramedic with an extended care designation may have more influence when it comes to treatment decisions. Or perhaps the rookie paramedic with the university degree balances her lack of experience as compared to her partner who was vocationally educated. It is conceivable that paramedics may have differing opinions than the nurse as to how to manage the palliative care patient, raising potential questions of jurisdiction and authority. Alternately, the police officer may not agree with the decision to leave Angie at home with a social work follow up. Both situations raise potential questions of jurisdiction and autonomous practice. Though hypothetical, the case scenario provides a realistic situation wherein a complex set of interrelations can be examined to further answer questions of paramedic professionalism and identity. 


\section{Discussion}

Paramedicine is a rich discipline with many layers of complexity.

Though it can be somewhat challenging initially to fully appreciate the application of social theory, establishing a theoretical perspective is essential to framing questions about paramedic practice. As other health professions have done before us, paramedic researchers must employ social theory to questions about paramedicine that study the social nature of our discipline. Certainly, Goffman offers a useful theoretical perspective to look at the front stage-backstage nature of paramedic work. His Impression Management Theory can also be used to better understand how contemporary paramedics see themselves as their role evolves. Similarly, Bourdieu's Theory of Practice can be used to help explore and define professional identity by applying his theoretical concepts of habitus, field and capital to paramedic practice. Future research using his framework could inform a better understanding of how paramedics make decisions as influenced by their unconscious guiding principles, formed by past experiences and education. It could also be used to explore the 'field' of paramedicine, especially during professionalisation. With their specific focus on relations and interactions among individuals, both Bourdieu and Goffman provide valuable contributions to the future study of paramedic identity formation.

Though the aim of this article is to present Bourdieu and Goffman, it is important to appreciate that this represents a very limited introduction to the plethora of theories in the social science field. One example is Identity Theory, wherein Stryker suggests that identity is constructed through our interactions with others sharing a similar role (53). Further to this, Hecht offers a Communication Theory of Identity, purporting that identity is enacted through our communication with others (54). Additionally, both van Maanen (55) and Hirschi (56) have developed theories on work or occupational identities that can be applied to research in this area. A final consideration is that social theory is only one of many lenses through which questions can be examined. Theory can also be applied from a range of fields of study including psychology, philosophy, communication and linguistics as examples.

\section{Conclusion}

Though paramedicine today is on the brink of exciting change through a transition to become a recognised health profession, discipline members are under significant stress. The identity of paramedics has evolved over time with more change inevitable as the nature of work shifts towards low acuity care, more women enter the field, and university education becomes the mainstay. Just as we look to research to answer clinical questions, we must employ research when searching for answers of a social nature. Social research begins with exploring social theorists such as Bourdieu and Goffman whose theoretical perspectives can be used to inform future research in this area.

\section{Conflict of interest}

The authors declare they have no competing interests. Each author has completed the ICMJE conflict of interest statement.

\section{References}

1. Bennett KJ, Sackett DL, Haynes RB, Neufeld VR, Tugwell $P$, Roberts R. A controlled trial of teaching critical appraisal of the clinical literature to medical students. Jama 1987;257(18):2451-4.

2. Williams B, Brown T, Onsman A. From stretcher-bearer to paramedic: The Australian paramedics' move towards professionalisation. Journal of Emergency Primary Health Care 2009;7(4):8.

3. O'Brien K, Moore A, Dawson DA, Hartley PR. An Australian story: Paramedic education and practice in transition. Australasian Journal of Paramedicine 2014;11(3):4.

4. Paramedics Australasia. The case for national registration for paramedics, 2014. Available at: www.paramedics.org/ advocacy/registration/the-case-for-national-registration-forparamedics/. [Accessed 15 June 2015].

5. COAG Health Council. Communique, November 6, 2015. Available at: www.paramedics.org/content/2015/11/COAGHealth-Council-Communique-Nov-6-2015-FINAL.pdf

6. McCann L, Granter E, Hyde P, Hassard J. Still blueicollar after all these years? An ethnography of the professionalization of emergency ambulance work. Journal of Management Studies 2013;50(5):750-76.

7. Capsey M. What is our unique selling point? Journal of Paramedic Practice 2010;2(6):242-4.

8. O'Meara P, Grbich CF. Paramedics in Australia: Contemporary challenges of practice. Frenchs Forest, NSW: Pearson Education Australia; 2009.

9. Heightman AJ. The 25-year history of EMS today: Always ahead of the EMS innovation curve. JEMS 2007;32(2):57-8.

10. Joyce CM, Wainer J, Piterman L, Wyatt A, Archer F. Trends in the paramedic workforce: A profession in transition. Aust Health Rev 2009;33(4):533-40.

11. O'Meara P, Ruest M, Stirling C. Community paramedicine: Higher education as an enabling factor. Australasian Journal of Paramedicine 2014;11(2).

12. LaCroix B. Characterizing job satisfaction and intent to leave among nationally registered emergency medical technicians: An analysis of the 2005 LEADS survey. J Allied Health 2009;38(3):84E-91E.

13. Brown WE, Dickison PD, Misselbeck WJA, Levine R. Longitudinal Emergency Medical Technician Attribute and Demographic Study (LEADS): An interim report. Prehosp Emerg Care 2002;6(4):433-9.

14.Powell MP. Recruitment and retention of emergency medical technicians: A qualitative study. J Allied Health 2005;34(3):153-62. 
15. Beaton RD, Murphy SA. Sources of occupational stress among firefighter/EMTs and firefighter/paramedics and correlations with job-related outcomes. Prehosp Disaster Med 1993;8(02):140-50.

16. Mitchell JT, Bray GP. Emergency services stress: Guidelines for preserving the health and careers of emergency services personnel. New Jersey: Prentice Hall; 1990.

17. LeBlanc VR, Birze A, Tavares W, et al. The association between posttraumatic stress, coping, and acute stress responses in paramedics. Traumatology 2011;17(4):10-6.

18.Zabjek A. Paramedic's suicide adds to questions: Emergency responders' deaths probed. Edmonton Journal; 2015.

19. Juanita P, Ben W. Murder-suicide paramedic 'should have been helped'. 2010. Available at: www.abc.net.au/news/201009-03/murder-suicide-paramedic-should-have-beenhelped/2246972. [Accessed 29 April 2015].

20. Ludwig G. Suicides among firefighters and paramedics. Firehouse 2011;36(1):35.

21. Lamoureaux M, MacPherson A. Canada's lack of first responder suicide stats is a national disgrace 2015. Available at: www.vice.com/en_ca/read/canadas-lack-of-first-respondersuicide-stats-is-a-national-disgrace-263. [Accessed 23 March 2015].

22. Hercelinskyj G, Cruickshank M, Brown P, Phillips B.

Perceptions from the front line: Professional identity in mental health nursing. Int J Ment Health Nurs 2014;23(1):24-32.

23. Goltz HH, Smith ML. Forming and developing your professional identity. Health Promot Pract 2014;15(6):785-9.

24. Burges Watson DL, Sanoff R, Mackintosh JE, et al. Evidence from the scene: Paramedicine perspectives on involvement in out-of-hospital research. Ann Emerg Med 2012;60(5) 641-50.

25. Palmer CE. "Trauma junkies" and street work: Occupational behavior of paramedics and emergency medical technicians. J Contemp Ethnogr 1983;12(2):162-83.

26. Tangherlini TR. Heroes and lies: storytelling tactics among paramedics. Folklore 2000;111(1):43-66.

27. Klee S, Renner K-H. In search of the "rescue personality". A questionnaire study with emergency medical services personnel. Personality and Individual Differences; 2012.

28. Wagner SL, Martin CA, McFee JA. Investigating the "rescue personality". Traumatology 2009;15(3):5-12.

29. Metz DL. Running hot: Structure and stress in ambulance work: Abt books; 1982.

30. Donnelly EA, Siebert D, Siebert C. Development of the Emergency Medical Services Role Identity Scale (EMS-RIS). Social Work in Health Care 2015;54(3):212-33.

31. Donaghy J. Equipping the student for workplace changes in paramedic education. Journal of Paramedic Practice 2010;2(11):524-8.

32. Michau R, Roberts S, Williams B, Boyle M. An investigation of theory-practice gap in undergraduate paramedic education. BMC Med Educ 2009;9(1):23.

33. Boyle MJ, Williams B, Cooper J, Adams B, Alford K. Ambulance clinical placements - A pilot study of students' experience. BMC Med Educ 2008;8:19.
34. Johnston T, MacQuarrie A, Rae J. Bridging the gap: Reflections on teaching interprofessional communication to undergraduate paramedic and nursing students. Australasian Journal of Paramedicine 2014;11(4).

35. Williams B, Fielder C, Strong G, Acker J, Thompson S. Are paramedic students ready to be professional? An international comparison study. Int Emerg Nurs 2014.

36. First S, Tomlins L, Swinburn A. From trade to profession-the professionalisation of the paramedic workforce. Journal of Paramedic Practice. 2012;4(7):378-81.

37. Yam BM. From vocation to profession: The quest for professionalization of nursing. Br J Nurs 2004;13(16):978-82.

38. Ihlen $\varnothing$. On Bourdieu: Public relations in field struggles. In: Ihlen $\varnothing$, Van Ruler B, Fredriksson M, editors. Public relations and social theory: key figures and concepts. New York: Routledge; 2009. p. 62-82.

39. Ihlen $\varnothing$, Van Ruler B. Introduction: Applying social theory to public relations. In: Ihlen $\varnothing$, Van Ruler B, Fredriksson M, editors. Public relations and social theory: key figures and concepts. New York: Routledge; 2009. p. 1-15.

40. Murphy M. Social theory applied 2014 [cited 2015 May 1]. Available at: http://socialtheoryapplied.com/what-is-socialtheory/.

41. Johansson C. On Goffman: Researching relations with Erving Goffman as pathfinder. In: Ihlen Ø, Van Ruler B, Fredriksson M, editors. Public Relations and Social Theory: Key Figures and Concepts. New York: Routledge; 2009. p. 119-40.

42. Morawski J. Livelihoods of theory: The case of Goffman's early theory of the self. Theory Psychol 2014;24(3):281-304.

43. Lewin S, Reeves S. Enacting 'team' and 'teamwork': Using Goffman's theory of impression management to illuminate interprofessional practice on hospital wards. Soc Sci Med 2011;72(10):1595-602.

44. Goffman E. The presentation of self in everyday life. USA: Anchor Books; 1959.

45. Campeau A. A space-control theory of paramedic scenemanagement: University of Toronto; 2007.

46. Forde $\mathrm{C}$. Emergency medicine triage as the intersection of storytelling, decision-making, and dramaturgy, 2014. Available at: http://scholarcommons.usf.edu/cgi/viewcontent. cgi?article $=6554 \&$ context=etd.

47. Tangherlini TR. Talking trauma: Paramedics and their stories. Jackson: University Press of Mississippi; 1998.

48. Palmer CE. Paramedic performances. Sociological Spectrum 1989;9(2):211-25.

49. Morberg S, Lagerström M, Dellve L. The school nursing profession in relation to Bourdieu's concepts of capital, habitus and field. Scand J Caring Sci 2012;26(2):355-62.

50. Fawkes J. Public relations ethics and professionalism: The shadow of excellence. Hoboken: Routledge; 2014. 37-61 p.

51. Davies $A$. The impact of simulation-based learning exercises on the development of decision-making skills and professional identity in operational policing. Charles Sturt University; 2013.

52. Bourdieu P. The logic of practice. Cambridge, UK: Polity Press in association with B. Blackwell; 1990. 
53. Stryker S, Burke PJ. The past, present, and future of an identity theory. Soc Psychol Q 2000;63(4):284-97.

54. Jung E, Hecht ML. Elaborating the communication theory of identity: identity gaps and communication outcomes. Commun Q 2004;52(3):265.

55. Van Maanen J. Identity work and control in occupational communities. 2010. Available at: http://dspace.mit.edu/ handle/1721.1/69852.

56. Hirschi A. Callings and work engagement: Moderated mediation model of work meaningfulness, occupational identity, and occupational self-Efficacy. J Couns Psychol 2012;59(3):479-85. 